\title{
Ante la ética de la fuerza o el tema de nuestro tiempo
}

\begin{abstract}
A los compañeros y amigos del equipo pastoral agustiniano de Móstoles, hostigados con pertinacia por la izquierda (especialmente por un concejal del PCE) mientras la derecha (presumiblemente la extrema derecha) les apedreaba y secuestraba el viejo coche de servicio parroquial y les motejaba con el clásico: «curas rojos no".
\end{abstract}

\section{La ética de la fuerza}

Ha sido Bernard Henry-Levy quien recientemente, al final de su escrito La barbarie à visage humaine, ha planteado el problema de la situación ética de nuestro tiempo al acusar de invalidez general e ineficacia final a los métodos usualmente socorridos en nuestro mundo por la paideia y las técnicas de transformación social actualmente vigentes con estas palabras: «Ya no tenemos política, ni lengua, ni recursos. No queda otra cosa que la ética y el deber moral»... «Ya es hora, acaso, de escribir tratados de moral» '. En definitiva, se ha llegado a una situación sin salida que Henry-Levy achaca a los políticos, necesitados, a su vez ahora, de una urgente desmitificación, tal como queda expuesto a lo largo de su última obra: Le Testament de Dieu ${ }^{2}$.

Se trataría fundamentalmente de liquidar con los mitos de la fuerza, y su valoración tan decisiva como medio de legitimación de la presencia humana interpersonal, especialmente en sus consecuencias institucionales. Para resumir el problema citaremos un texto elocuente de Jean Nabert: «La misma

1. B. Henry-Levy, La barbarie à visage humaine. Trad. castellana de E. Simons, Barcelona 1978,186 y 192.

2. B. Henry-Levy, Le Testament de Dieu. Trad. italiana de F. Baldini, E. Cerutti y L. Rizzo, Milano 1979. Cito siempre por ella. 
conclusión se desprende si se examina la repercusión del éxito en las conciencias que lo testimonian y que encuentran cierta dificultad para librarse del pensamiento de que una causa victoriosa en las luchas humanas no puede ser radicalmente mala o condenable. En el mismo vencedor, el triunfo tiende a recrear una buena conciencia, a sofocar los escrúpulos, tanto más que la situación y las otras conciencias se muestran dóciles de hecho y parecen ofrecerle una ratificación» ${ }^{3}$. Por tanto la norma es que el vencedor imponga sus propios y «mejores» criterios y objetivos. Ahora bien, en este caso el problema propiamente no se plantearía en torno a la bondad o maldad de una opción humana o social, se trataría simplemente de averiguar, con la mayor astucia posible, quién será el ganador para el futuro inmediato.

En tales circunstancias la política se opone a la moralidad como la ciencia a la ingenuidad. Con términos más claros y tajantes E. Levinas sentenciará: «Aceptaremos fácilmente que es cuestión de gran importancia saber si la moral no es una farsa» ${ }^{4}$.

¿Nos atendremos a los hechos, a lo que, de hecho, es o apostaremos por lo que debe ser? No puede hablarse aquí de idealismo pues sabemos que cuando la aparición de una utopía se constituye en peligro social éste ocurre a causa de la eficacia de lo pretendidamente utópico. Por lo demás la eficacia tampoco constituye un verdadero criterio: «Nuestra protesta se dirige contra la idea de que, en las luchas históricas -incluso a nivel del 'Espíritu Universal' - la victoria corresponderá irremisiblemente a la causa justa, entendiendo por 'causa justa' precisamente aquella que vencerá; con ello la afirmación de que 'el futuro será de los justos' se reduce a una mera tautología, pues el que decide quiénes son los justos es aquel a quien pertenecerá el futuro» ${ }^{5}$.

También en el momento actual ha conseguido gran simpatía la consigna de Max Stirner: Si puedes ser una cosa, y tienes fuerza para serla, debes serla; o transformada en guía para la acción inmediata se diría así: si puedes hacer una cosa y tienes fuerza para hacerla, debes hacerla. Con sus mismas palabras: «¿Aspiráis a la libertad? ¡Locos! Tened la fuerza, y la libertad vendrá» ${ }^{6}$. Así los oprimidos bendicen los métodos de sus opresores. Solamente lamentan no tenerlos aún a mano. Como se ve aquí el deber depende claramente de si se tiene o no se tiene la fuerza suficiente. No se hace por tanto pregunta alguna sobre los objetivos y su validez, el único problema es la viabilidad o no de la realización técnica del golpe, por así decirlo.

3. J. NABert, Eléments pour une Ethique. Paris 1963, 43. Trad. mía.

4. E. Levinas, Totalité et infini. Trad. castellana de D. E. Gillot, Salamanca 1977, 47.

5. L. Kolakovsky, Der Mensch ohne Alternative. Trad. castellana de A. P. Sánchez Pascual, Madrid 1970, 99.

6. M. Stirner, Der Einzige und sein Eigentum. Trad. castellana de E. Subirats, Barcelona 1974, 2a., 131; también: 81, 114-115, 148, 169, 223. 
Estamos en plena razón instrumental pura: Algo es razonable si resulta prácticamente factible. Nadie dudará que esta razón instrumental cumple plenamente y con toda ironía la definición de la política como «el arte de lo posible», que de este modo toma sobre sí un aire de cinismo incalificable ? ${ }^{\text {. La }}$ capacidad de dominación del mundo, de los hombres, de todas las cosas se instaura como criterio ético. Es la ideología de los hechos denunciada por T.W. Adorno ${ }^{8}$. Frente a ella el pensamiento crítico resulta ridículo mientras el relativismo demagógico se impone con el consumo: «El relativismo es materialismo vulgar, pensar estorba los negocios» ${ }^{9}$.

De ahí la enemiga mortal entre sociedad de consumo y razón teórica. No se trata de un sano anti-intelectualismo, como es frecuente suponer, es el antipensamiento mismo. Cuando la fuerza brutal, la fuerza de los hechos, de lo natural, ha conseguido anular o cautivar suavemente la racionalidad, la brutalidad campea por sus fueros hasta que por fin invade el pensamiento. Sartre lo había descrito así: «Si le proverbe dit: 'mens agitat molem', la bêtise sera moles installée dans la pensée; una pensée dominée par le corps, c'est-à dire par le nature» ${ }^{10}$.

Estamos ante la exterioridad monda y lironda, en el teatro de las máscaras y la vida elemental de la que nos previno Kierkegaard al escribir: «El hombre inmediato -en cuanto en la realidad puede darse una inmediatez totalmente desprovista de reflexión - no está más anímicamente determinado y su Yo y él mismo no son más que un simple algo dentro del conjunto de la temporalidad y la mundanidad, en estrecha interdependencia con lo otro... y solamente teniendo una apariencia ilusoria de que haya algo eterno en él. De esta manera, el Yo se enlaza inmediatamente con lo otro, deseando, anhelando, gozando, etc., pero en definitiva siempre pasivo. Incluso cuando anhela, este Yo no es más que un dativo, como le pasa al niño que siempre está diciendo 'para mí'. Este hombre no conoce otra dialéctica que la de lo agradable y lo desagradable, y sus conceptos favoritos son: dicha, desgracia y destino" ${ }^{11}$.

Como nos dice el mismo pensador esta situación es enormemente frágil y lleva fácilmente al cinismo. Es una existencia ensoñadora con despertares amargos, la equivocación de soñar por un querer ser absoluto sin sentido que deviene absoluto no-ser fallido en su fin y su objetividad por confusión de caminos. Son las máquinas deseantes a pleno rendimiento aplicadas en la propia destrucción.

7. D. SÖlle, Wählt das Leben. Stuttgart 1980, 15.

8. T. W. Adorno, Crítica, cultura y sociedad. Trad. castellana de M. Sacristán, Barcelona 1970,78 у 29.

9. T. W. Adorno, Negative Dialektik. Trad. castellana de J. M. Ripalda, Madrid 1975, 43.

10. J. P. Sartre, «Sur la bêtise», un texte inédit de Jean Paul Sartre, Magazine Littéraire, 103-104 (1975) 32.

11. S. KieRKEGARD, La enfermedad mortal. Trad. castellana de Ed. Guadarrama, Madrid $1969,110$. 
Tal es el ideal del hombre práctico normal de nuestro tiempo. Es la fuerza natural de cada medio interiorizada y propuesta como imperativo fundamental. En su base está la determinación de ser «como todo el mundo»: «Ainsi la bêtise est à expliquer à partir de la normale. Et comme la normale est normati$v e$, comme elle est fait et valeur en même temps, la bêtise est à la fois réalité du non-être et antivaleur'" ${ }^{12}$. De este modo la alianza entre brutalidad y normalidad se presenta como ética dominante, o mejor aún, es ahora la única y verdadera realidad. Es la plenitud de la falacia naturalista ${ }^{13}$ y la a-nomía perfecta, la vida desencantada de la ciudad sin ley ${ }^{14}$.

El discurso humano, en su sentido más propio de racionalidad, se convierte en un mero discurrir según la ley de los tiempos y los mundos imperantes. Y como lo que es, debe ser, sin otra posibilidad ni diferencia y viceversa, el hombre y su mundo han ganado una nueva divinidad pues la racionalidad, sustraída a la dialéctica finitud-infinitud, se diviniza y el hombre se carga de razón absoluta, de modo que ya nunca puede equivocarse ni puede fallar jamás: No hay posibilidad de reconocer errores y mucho menos pecados. El complejo de Dios queda así plenamente realizado ${ }^{15}$, en pacífica posesión de sí mismo, a no ser que otros semejantes se despierten con parecidas pretensiones, lo que no sería de extrañar, y los soñadores entrechoquen. Si eso ocurriera produciría dramáticamente la división del mundo del soñador entre los dominios de los objetos y los dominios de la conciencia ensoñada. Y de una forma más escandalosa aún el hombre comenzaría a preguntarse por lo falso y lo verdadero, y en definitiva, por el bien y por el mal.

Pero vayamos un poco más despacio... Aquí dejamos la palabra a Michael Novak: la» 16 .

1. «Le langage ordinaire est un langage d'objets: de lui, d'elle ou de ce-

2. «Le langage ordinaire est, en outre, d'un point de vue religieux, naturellement idolâtre»" ${ }^{17}$.

3. «... le langage emprunté au monde des objets peut nous amener par erreur à penser que la conscience est comme la perception des sens ou que le 'monde' des sujets est une imitation du monde des objets» ${ }^{18}$.

12. J. P. SARTRE, «Sur la bêtise», 31-32.

13. E. HusserL, Ideen, I. Trad. francesa de P. Ricoeur, Paris 1950, 87-183. J. MuguerzA, La razón sin esperanza. Madrid 1977, 175 y ss. J. SEARLE, Speech acts: An essay in the Philososophy of Language. Trad. castellana de L. M. Valdés V. Madrid 1980, 138 y ss.

14. H. KUnG, Christ sein. Trad. castellana de J. Ma. Bravo N. Madrid 1977, 42 y ss.

15. H. E. RICHTER, Der Gotteskomplex. Reinbek 1979. W. SCHMIDBAUER, Alles oder nichts. Úber die Destructivităt von Idealen. Reinbek 1980.

16. M. Novak, Belief and Unbelief. Trad. francesa de J. Chambert y D. Piveteau, Paris 1969, 92.

17. M. NovaK, Idem, 93.

18. M. NoVAK, Idem, 143. Habermas lo dice así: «Mir scheint, dass die Frage nach dem on- 
Así es como al buscar un sentido esperamos encontrar unas cosas. La racionalidad queda de antemano cosificada y cristalizada a la expectativa de una respuesta en cadena teórico-deductiva matematizable, o suspendida en el sueño utópico de un programa práctico total, definitivo y permanente. Y sin embargo, también aquí es posible rechazar los ídolos, volver la espalda a las ilusiones ${ }^{19} \mathrm{y}$ continuar fiel a un auténtico deseo de verdadera racionalidad más allá de todas las degradaciones, aun si éstas no son precisamente ni pequeñas ni poco frecuentes.

Si anotamos como muy importante en nuestro tiempo las propuestas del realismo y la sinceridad, no olvidaremos que aquél se convierte fácilmente en la máscara del cinismo; en alianza secreta con la destrucción de la vida, es la caída de la verdadera resistencia frente a la insensibilidad, la insolidaridad y la muerte ${ }^{20}$. La sinceridad termina por ser «une évasion loin de la question fundamental» ${ }^{21}$. Tales sinceridades se revelan fácilmente como aceptación inmediata de los estados emocionales transitorios, de los datos brutos primarios de nuestra oferta y nuestra demanda cultural; y ya sabemos su destino cuando se toman por verdades inefables, autoevidentes, en vez de realizar su misión de señales presentadas a un parlamento instintivo preparado para la serenidad de las decisiones ${ }^{22}$.

En este asunto, para tocar solamente un aspecto del problema, el equívoco freudiano es muy fuerte. El psicólogo de Cambridge, James Moore, no cederá terreno alguno al respecto: «No hay ninguna duda que en la crisis actual del adolescente, la causa original no es en absoluto el rechazo, la represión de las fuerzas afectivas e instintivas (como era el caso hasta la última guerra) sino, por el contrario, un 'dejar hacer' en la educación del niño, inconcebible sólo hace algunos años» ${ }^{23}$.

Dentro del realismo y la sinceridad conviene recordar la problemática de la propia realización como una de las justificaciones más socorridas en nuestro tiempo. Citaremos a este respecto un texto amplio pero extraordinariamente elocuente: «En fin, puede que otras personas tomen sus designios

tologischen Status von Tatsachen überhaupt falsch gestellt ist: die Unterstellung, dass Tatsachen in analoger Weise 'etwas sind' wie Objekte, die wir erfahren oder behandeln, ist strenggenommen sinnlos»: J. HABERMAS, Erkenntnis und Interesse. Mit einem neuen Nachwort. Frankfurt a. M. 1977, 4a. 385.

19. M. NovaK, Idem, 155 .

20. D. Sólle, Wahlt das Leben, 15: «Das Leben wählen ist gerade die Fähigkeit, sich nicht abzufinden mir der selbstverständlichen Zerstörung von Leben, di uns umgibt, und mit dem selbstvertăndlichen Zynismus, der uns begleitet». Subrayado mío.

21. M. NovAK, Idem, 165 .

22. K. LORENZ, «El gran parlamento de los instintos». Sobre la agresión: el pretendido mal. Trad. castellana de Félix Blanco, Madrid 1971, la., 98-123.

23. M. LANCELOT, Je veux regarder Dieu en face. Vie, mort et résurrection des Hippies. Paris $1968,273$. 
pragmáticos de la ciencia y de la comunidad humana, como los elementos más reales de la experiencia del hombre. Lo que cuenta para ellas es realizarse ellas mismas, acertar en una carrera honorable, ser lo mejor posible en su profesión, tener buenos amigos, comer bien y conseguir, por la acción política y social, que el mayor número posible de personas puedan tener estas mismas excelencias. En este caso, la igualdad de oportunidades, la franqueza, la justicia, la lucha contra la ignorancia y la enfermedad, la reforma del orden político, económico, social y familiar forman los ideales que rigen la vida. Pero, si lo pensamos bien, parece que para concretar tales designios y para hacer una elección juiciosa entre estos objetivos diversos, se necesita tener una visión sobre qué es propiamente el hombre. Y decidir qué es el hombre es recurrir a la conciencia original, a la penetración psicológica, al juicio crítico y a la fidelidad al deseo fundamental de ser racional» ${ }^{24}$.

Es preciso subrayar fuertemente la implicación, previa a toda decisión vital, de una imagen del hombre a realizar y de todo un esquema antropológico consecuente a la misma. Como dijera Keynes en economía, el que no cree seguir a ningún maestro se dirige siempre por el peor de todos; eso mismo ocurre en el planteamiento general de la vida. Esta necesita de la racionalidad tanto como el pensamiento pertenece a la vida. Por eso conviene ahora recordar unas palabras proféticas de Ortega: «La razón no puede, no tiene que aspirar a sustituir la vida.

Esta misma oposición, tan usada hoy por los que no quieren trabajar, entre la razón y la vida es ya sospechosa. ¡Como si la razón no fuera una función vital y espontánea del mismo linaje que el ver y el palpar! ....al destronar la razón, cuidemos de ponerla en su lugar» ${ }^{25}$.

Esperamos que no hará falta insistir en lo inadecuado del pragmatismo utilitario como figura concreta del hombre meramente funcional y duramente industrioso. Pero sí conviene saber claramente de su vinculación absoluta con el poder industrial y sus mecanismos productivos ${ }^{26}$. Aquí encuentra toda su verdad la antigua sabiduría que nos dice: «De donde tienen su origen los seres de allí les viene la corrupción, según el destino, pues se dan unos a otros retribución y pena por su injusticia según el orden del tiempo» ${ }^{27}$. Donde cree el hombre encontrar su salvación, su propia realización, de allí mismo recibe su destrucción. La sociedad industrial de nuestro tiempo lo comprueba cada día.

En definitiva, el realismo no se alcanza por un experimentalismo primario: «Le réel c'est donc ce qu'on atteint, non pas immédiatement par extraversion mais d'une manière indirecte par la réflexion»" ${ }^{28}$.

24. M. NovaK, Idem, 166.

25. J. Ortega y Gasset, Meditaciones del Quijote. O. c. I., Madrid 1947, $1^{\text {a }} 253$ y 254.

26. M. NovaK, Idem, 168.

27. Primer texto crítico de la filosofía griega, obra de Anaximandro: G. S. KIRK, J. E. RAVEN, The presocratic philosophers. Trad. castellana de J. García Fernández, Madrid 1969, 169.

28. M. Novak, Idem, 169. 
Con esto no se trata de hacer espiritismo sino de superar la brutalidad elemental que siempre tiende a volver por sus fueros tras los más extraños velos. La reflexión crítica nos protege contra la alucinación y la vana ilusión: «Nous nous protégeons contre les illusions, les hallucination et les imaginations en soumettant à la réflexion critique ce que nous paraissons toucher, voir ou entendre ${ }^{29}$. Ser fiel a la realidad es serlo a la inteligencia, a lo tangible en cuanto inteligible y vicerversa; sólo la ideología brutal, formalista o materialista, exige adhesión creyente sin vida como forma suprema de destrucción. Así es como la racionalidad se vuelve estereotipo y se confunden las palabras con las cosas, los sistemas de información con la realidad, solamente aludida y siempre lejana al hombre mismo.

Por el contrario, la realidad más verdadera resulta casi siempre, al final, propiamente inabarcable, en cierto sentido misteriosa, en trance permanente de desvelamiento y a la vez oculta e inexpugnable a todas nuestra panoplias categoriales. Tal es la dialéctica del conocimiento humano: conocer, vivir, volver a conocer y volver a convivir.

Terminamos este pequeño rodeo con una importante advertencia de $\mathrm{S}$. Kierkegaard al respecto: «La inmediatez... es algo enormente frágil, y por eso cualquier 'quid nimis' que exija reflexión es capaz de llevar hasta la desesperación al hombre que tenga toda su vida en ella» ${ }^{30}$.

Para la irracionalidad consumista triunfante tampoco este resultado es demasiado dramático puesto que también el suicidio contribuye a rebajar el paro, y es una "pura y simple coincidencia» que al sujeto humano le vayan estas cosas. Las gallinas se suicidan menos... por ahora; quizá comiencen también pronto...

Entre tanto podemos repetir en alto, según suelen hacer los niños, para despistar y quizá para quitar el miedo, las grandes palabras del momento: autonomía, solidaridad, bien común, democracia (si se quiere), pobres, éxito, poder, amor, justicia, igualdad, partidos (que hay que tomar), lucha, libertad, pueblo, progreso, religión o ateísmo, pobres, vida y fiesta. De momento con estas pocas palabras basta para no hacer un repertorio demasiado amplio y poco memorizable.

\section{La situación actual}

A fin de evitar, de antemano, malentendidos conviene reconocer, de buen grado, los logros importantes de la humanidad; conseguidos por muy diversos

29. M. NOVAK, 170.

30. S. KIERKEGAARD, La enfermedad mortal. Trad. castellana de E. Guadarrama, Madrid 1969, 111. 
métodos, medios o formas, no siempre igualmente dignos. Por esto, y para resumir, citaré el juicio del sociólogo P.L. Berger cuando dice: «Los críticos del capitalismo tienen razón al rechazar políticas que aceptan el hambre de hoy prometiendo la abundancia de mañana (y tienen razón al rechazar dicha promesa). Los críticos del socialismo tienen razón al rechazar políticas que aceptan el terror de hoy prometiendo el orden humano de mañana (y tienen razón, igualmente, en cuestionar la credibilidad de ese mañana) ${ }^{31}$.

Para mayor claridad es necesario quizá añadir que: «En principio, es imposible 'concientizar' a nadie, porque todos andamos a tientas en el mismo nivel de conciencia, un nivel muy confuso, por cierto» ${ }^{32}$. Nadie negará tampoco la necesidad de nuevas mediaciones universales y concretas aunque esta última tarea atañe al parecer mucho más directamente a las labores de los técnicos ${ }^{33}$. Pero más allá de estos acuerdos tan generales, ¿qué hacer?

De entrada denunciar de nuevo el retorno de los brujos como un acontecimiento desorientador permanente. La brujería es el cultivo del vicio como virtud ${ }^{34}$, la ejemplarización de ésta como signo de lo malo y lo anti-humano. No es por causalidad que Susan Sontag haya podido escribir: "No lo disculpes - pedía a Larsen-. Respeta su opción y no trates de hacer bueno lo que es malo. No interpretes nada. Lo más molesto de la sensibilidad moderna es su urgencia por excusarse y hacer que una cosa signifique otra» ${ }^{35}$.

Esta con-fusión del bien y del mal en la conciencia contemporánea produce la analgesia de nuestra civilización fundada precisamente en una insensibilidad más originaria ${ }^{36}$. No hace falta acentuar más la pérdida de imaginación y la incapacidad para sentir a, y con, los otros aun los más próximos o simplemente prójimos.

Si nada es bueno ni nada es malo o todo es bueno y todo es malo como parecen querer demostrar o simplemente afirmar muchos, entonces todo es igual y por tanto no puede plantearse razón alguna de preferencia o decisión. Así llegamos directamente al escepticismo actual. La disolución de la conciencia ética de la humanidad hace imposible toda base de solidez permanente;

31. P. L. Berger, Pyramids of sacrifice. Political Ethics and Social Change. Trad. castellana de J. García Abril. Santander 1979, 12. Original castellano subrayado.

32. P. L. Berger, Pyramids, 12.

33. P. L. Berger, Pyramids, 13.

34. E. F. Schumacher, Good Work. Trad. alemana de K. A. Klewer, con el significativo título Das Ende unserer Epoche. Reinbek 1980, 51-52: “'Heuchelei ist' - Wie der Herzog de la Rochefoucauld vor dreihundert Jahren anmerkte- 'die Huldigung des Lasters an die Tugend'. Man ubersehe nicht die Beceutung, die darin liegt, dass heute jegliches Gewaltherrschaftsystem als Demokratie ausgibt und man alle Eroberung als Befreiungen und alle Willkürakte als die Gerechtigkeit des Volkes hinstelli':'.

35. S. Sontag, The benejacior, Trad. castellana de edit. Lumen, Barcelona 1974, 124. Subrayado mío.

36. D. SólLE, Sympathie. Theologische-politische Traktate. Stuttgart 1978, 32. 
nuestras venerables razones morales se han, al parecer, evaporado. Se pasa de todo pero no se cree en nada o se pasa de todo porque no se cree en nada. Las creencias, aun en el sentido fundamental orteguiano parecen disolverse. No hay aquí nada parecido a una 'santa indiferencia' manifestativa de una disponibilidad profunda y generosa para el amor servicial sino solamente un escepticismo supremo, muchas veces innominado, pero que muestra fácilmente su rostro de cinismo absoluto en los momentos más difíciles.

Puede decirse que el hombre de nuestro tiempo ha quedado desvocacionalizado, nadie le llama a nada, ni nadie llama a nadie; el paro, además de laboral, es metafísico. Si la vida tiene un sentido puede decirse que: «jamás se ha visto/ jamás se ha oído/ jamás se ha olido, ni tocado, ni saboreado/ jamás ha faltado pero/ jamás se ha oído mencionar;/ jamás se ha tenido idea de él/ jamás se ha soñado/ jamás se ha buscado/ jamás se ha ocultado, / ¿es esto un problema?» ${ }^{37}$.

En esta situación debe adelantarse que el primer paso a dar, para ser realistas y libres, es guardarse de los encantadores que confunden la verdad con la victoria y el valor con lo vigente tras el paso de las fuerzas armadas, sean éstas de la clase que sean, y todo ello: «Significa aderire a valori che, per quanto scherniti e smentiti dall'innumerevole Fatto, continuano ancora a valere, a credere al loro sovrano Diritto. Significa stabilire che ci sono un Bene e un Male, non necessariamente in ogni luogo e in ogni tempo ma independentemente dal tempo e sia che il tempo ratifichi sia che no rarifichi la loro ostinazione a essere» ${ }^{38}$.

Por tanto el modo más actual de estar presente en la auténtica corriente de la historia de nuestro mundo es buscar este discernimiento. Esta es también, así lo esperamos, la verdadera filosofía de la historia. Como lo ha propuesto un personaje dialogante de L. Kolakovski: «Los valores morales permanentes que se han ido formando en el curso de la evolución humana son para nosotros el apoyo más firme cuando la realidad exige de nosotros una elección, que, a la postre, tiene carácter moral. En todo caso, tales valores son más dignos de confianza que toda filosofía de la historia. Esta es la razón por la que yo insisto definitivamente en mi opinión.

- ¿Suceda lo que suceda?

-Suceda lo que suceda» ${ }^{39}$.

Este punto primero de nuestra reconsideración de la conciencia personal

37. Poema utilizado por el antipsiquiatra R. D. Laing, y citado por D. SöLlE, Wählt das Leben, 35: «never saw it / never heard it / never smelt it, touched it or tastet it / never felt it / never heard it mentioned / / never had any idea of it / never dreamt of it / never wanted it / never missed it / is there a problem?».

38. B. Henry-Levy, Le Testament, 225. Puede verse sobre esta obra: J. Garcia Roca, «Liberación y testamento de Dios», Iglesia Viva, 85 (1980) 43 y ss.

39. L. KolaKovSKy, Der Mensch, 76. 
y social contemporánea parece resumirse y vertebrarse en la Nueva Filosofía, concretamente en estos enunciados de André Glucksmann: «La crítica del totalitarismo muestra una molesta tendencia a resumirse siempre en la crítica del totalitarismo ajeno:... El totalistarismo son los demás» ${ }^{40}$. Esta afirmación, utilizada por todos como disculpa, resume toda nuestra época y con estas cantinelas llevamos ya desgraciadamente muchos años, y aun siglos. Ya es hora de entonar el canto de la responsabilidad colectiva y solidaria.

La crítica barata, por ambos bandos, a la Nueva Filosofía nos hace pensar más aún en el valor de su independencia y la necesidad plena de su presencia actual. Como el cliché que más se ha corrido socialmente es el 'ideología de la nueva derecha' citaré a un personaje que si resultara sospechoso de tal proclividad habría que pensar en la mala fe de cualquier interlocutor aparentemente válido. Se trata de A. Negri y dice así: «Personalmente, no tengo nada que ver con los llamados 'nouveaux philosophes', pero debo manifestar que me siento un poco desconcertado cuando veo a representantes de los partidos históricos de la clase obrera, desde siempre atraídos por el binomio iluminismo/stalinismo productivo, iinsultar a los jóvenes filósofos por haber denunciado esta conexión mistificante!» ${ }^{41}$.

La Nueva Filosofía es un grave interrogante a nuestra época al poner entre paréntesis su misma objetividad que pasa por ser el único mundo real. Esto no puede admitirlo el político, pues éste no puede dudar al tener gracia de Estado eficaz. Los poderes políticos son la fatalidad. Escuchemos a B. Henry-Levy: «¿De dónde procede, para comenzar, esta pregunta que formulo del modo más abrupto e inflexible: qué es exactamente la realidad y cuál es su estatuto político? Los políticos se abstienen justamente de hacerla. Viven en la certidumbre de que la realidad está poblada de cosas, de que estas cosas son fósiles, que estos fósiles son fragmentos, concreciones de la naturaleza, congelados y solidificados desde siempre; que por más que la Historia marque con sus zarpas y la pintarrajee con sus jeroglíficos, sigue lisa y lavada, vidriosa y cristalina, como un espejo sin azogue donde se refleja su voluntad; que no constituye, que no provoca problemas, por qué está ahí, ante ellos, en una muda interioridad, materia pasiva y letárgica que se ofrece a sus cálculos y se abre a sus proyectos. Esta es literalmente la 'Realpolitik' esta creencia en la realidad, esta piedad para con el mundo, esta naturalización dé su espacio»» ${ }^{42}$.

40. A. Gluchsmann, Les maîtres penseurs. Trad. castellana de J. Jordá. Barcelona 1978, 233. Subrayado mío.

41. A. Negri, Dominio y sabotaje. Trad. castellana de J. S. Grau. Barcelona 1970, 40-41. De paso digamos que las acusaciones contra la Nueva Filosofia pueden volverse fácilmente contra sus creadores, F. SAvater, Panfleto contra el Todo. Barcelona 1978, 185 ha visto la invalidez de algunas críticas. Para una crítica de la Nueva filosofía que raya a su vez en el lenguaje panfletario del que acusan a los Nuevos Filosofos puede verse: F. Aubral, DelcourT, X., Contre la nouvelle philosophie. Trad. castellana de J. Mejía, México 1978.

42. B. HENRY-LeVY, La barbarie, 47-48. 
La realidad propiamente no existe, sino que se produce constantemente por los dueños de la tecnología; por una parte se dice que hay que actuar según el interés objetivo de la realidad y por otra se modela la realidad en función de determinados intereses, ante el poder no hay ni metafísica ni fondo ni fundamento, ni realidad primigenia: «Porque el problema no reside en esto, es infinitamente más radical: el poder no se apropia el mundo, lo engendra constantemente en el conjunto de su dimensión. No ex-propia a los hombres sus moradas, les fija residencia, excava y fortifica sus nichos, donde, literalmente, arraigan. Lejos de desgarrar con malignidad la urdimbre de su tejido social, es el sastre que corta el paño de toda realidad. No es el mundo lo que él deshace, a reserva luego de volverlo a hacer, sino que, al contrario, lo hace sin referente y sin precedente. Esto es más difícil de pensar, el tema más arduo de un pesimismo consecuente; no se trata de esta realidad que roe y exfolia el Amo, sino de la forma misma de la realidad que él siempre engendra; si la realidad del capital, es como se sabe, desesperante, vano es achacar a otro sus propios sueños y esperanzas; lo propio del poder, en una sola palabra, consiste en su función, y en su vocación de modelar y recortar la realidad en cuanto tal» ${ }^{43}$.

La realidad entonces aparece como dada desde siempre mientras que todo cuanto parece propiamente originario es de hecho producto determinado de los poderes que pueblan el mundo y lo matrizan como ángeles invisibles pero siempre eficaces en sus labores. La fatalidad, el destino, el realismo es el nombre escondido de los poderes, de los políticos, de los príncipes rectores de este mundo. Ahora la naturaleza ya no es sino la realidad creada por la política presentada como eterna.

Por otra parte el revolucionarismo, como ha dicho Glucksmann, es ya una carrera más, "carrera de revolucionario profesional, carrera de político científico. La revolución se convierte en una ciencia: La ciencia del Estado, de la programación de una humanidad feliz incluso pese a ella» ${ }^{44}$. En esta situación: «Sólo el político escapará a la reprobación general, dado que él habrá tomado de los señores del pensar esta ciencia general de la reprobación que hace tabla rasa y autoriza a volver a empezar el mundo a partir de cero, arrancando las viejas ideas, los viejos prejuicios y las cabezas» ${ }^{45}$.

43. B. HeNRY-LeVy, La barbarie, 50 .

44. Por eso también la desconfianza con relación a los partidos es insuperable: «Podemos pensar sin un comité central en la cabeza». Son declaraciones del Nuevo Filósofo revolucionario A. Glucksmann a Y. Gentil-Biachis, Vuelta, 18 (1978) 49. En la misma línea están las últimas entrevistas de Sartre. También R. Bahro nos asegura: «Die Partei wird ihr Erstgeburtsrechts verlieren, wenn sie nicht in der Lage ist, sich und den Staat gründlich, d. h. sozial statt bürokratisch, zu erneuern»: R. BAHRo, Die Alternative. Zur Kritik des real existierenden Sozialismus. Reinbek 1980, 115.

45. A. Glucksmann a Y. Gentil-Biachis, Vuelta, 18 (1978) 49. 
Es preciso anunciar de nuevo que el valor de las personas es insuperable: «el partido de los fusilados se ha convertido en el partido de los fusiladores» denunciaba Sartre ${ }^{46}$; o como ha dicho Henry-Levy la ética comienza cuando aceptamos el principio universal de que una vida es una vida y no se puede destruir con ningún pretexto ni afrentar su dignidad por ningún bien pretendidamente mayor, y que por tanto todo el que mata es ya un reaccionario ${ }^{47}$.

Si vamos al fondo de las cosas vemos cuán difícil es que una causa justa sea apoyada por su propio y verdadero valor. Así en el caso del Vietnam, al fin y a la postre, se presionaba, nos declaran meditativos algunos de los grandes protagonistas de aquellos tiempos «no sólo porque estuviéramos al lado de las víctimas sino porque estábamos al lado de los presuntos vencedores» ${ }^{48}$. De ahí el significado extraordinario de la vuelta actual a lo no brillante, a lo abandonado y pequeño, y por tanto poco utilizable y apenas nada rentable de cara a la opinión pública. Esta suele ocuparse de las injusticias apropiadas para rentar más poder a los distintos bloques, mientras se olvida fácilmente a los más marginados por su escasa rentabilidad en la correlación de fuerzas establecidas.

\section{El mundo que viene y ya está aquí}

En este momento surgen, en interacción dialéctica con el sistema, las nuevas generaciones que llegan en plan de triunfadores. Se ha prometido la felicidad universal, como corresponde a una economía de bienestar, pero este paraíso o no ha llegado del todo o es muy difícil y casi imposible de mantener. Esto ha desatado la envidia (Neid), la avaricia (Geiz) universal y la intemperancia (Unmässigkeit) brutal del poder y la fuerza ${ }^{49}$.

Como máquinas deseantes los hombres de nuestro tiempo corren tras los fantasmas de la promesa, muy próxima a la realidad, pero en definitiva, fantástica, como el burro tras la zanahoria. De ahí que los ideales de la penúltima generación parezcan una burla cruel a la última. Esta reacciona, en principio, con un fuerte complejo de Sansón: «todos hemos de perecer para salvar a nuestro pueblo», que se resuelve en los años 70 como complejo de Noé, es: «la ética de la supervivencia como especie, el tinte ecologista que inevitablemente distingue a todos los movimientos y acciones en los que participan los jóve(1980) 38

46. Citado por R. Rossanda, (Dossier Sartre), "Una vida espléndida», El Viejo Topo, 40

47. B. Henry-Levy, Le Testament, 235-236 y 179.

48. D. Cohn-Bendit, F. RenberG, A. Glucksmann, «La soledad del Vietnamita», El viejo Tоро, 40 (1980) 38.

49. E. F. SCHUMACHER, Good Work, 48. 
nes" ${ }^{50}$. Solamente esta nueva generación, siempre según ella misma, es auténtica y verdadera, no farsante ni hipócrita como las demás, y pertenece ya propiamente a los seres realmente humanos. Los anteriores y antepasados deben ser deshechados, dejados fuera del Arca.

En general, se trata de una generación bien alimentada y bien cuidada por sus antepasados, por lo que no es de extrañar su conciencia de superioridad: deben ser muy importantes pues fueron tan bien tratados. Al pasar de todo, se implican, de paso, en un juicio de valores ajenos. Al vivir ensimismados (son los Narcisos) no pueden conceder tampoco excesiva importancia al asunto. Lo que no obsta para que se muestren: «independientes e impositivos, difíciles de intimidar (puesto que les han servido tanto, sus vidas deben ser muy importantes y no serán tocadas), con tendencia a impresionar y a arrebañarse (formar rebaño y aprovecharse de todo), brillantes y hedonistas, fantasiosos y fantásticos, perfeccionistas buscan con constancia la propia satisfacción, manipuladores y oscilantes, con poco sentido de la culpa, necesitados de la aprobación ajena y encantadores, siempre adolescentes, bastante exhibicionistas, y en definitiva: «El narciso - concluye Lasch- es el consumidor por excelencia» ${ }^{51}$.

Se trataría también de una reacción de secreta venganza a la burlá te la sociedad feliz: han crecido en un mundo que los alimentaba bien y cuidaba con esmero pero les ha metido en una vida sin demasiado sentido para ellos; por eso no comprenden a las otras generaciones y tienen miedo de intentarlo: «les es difícil aprender algo; por eso saben tan poco y muestran tanto resentimiento. Este resentimiento es comprensible; lo triste es su falta de coraje moral» ${ }^{52}$. Además, como ya anunciara Sartre: «diríase que, antes que una edad de la vida, la juventud fuera un fenómeno de clase, una prórroga de irresponsabilidad concedida a los hijos de papá, puesto que los obreros pasan sin transición de la adolescencia a ser hombres" ${ }^{53 .}$

Aquí campa por sus fueros Q mejor por sus desafueros el mundo de la fantasía frente a la necesidad urgente de esfuerzo; es un soñar en lugar de ser y hacer; la pimpante situación económica lo permite. Aquí se encuadra también la crisis del trabajo. Este ha dejado de ser un medio de salvación ${ }^{54}$ pues ya no

50. A. de Miguel, Los narcisos. El radicalismo cultural de los jóvenes. Barcelona 1979, $2 a ., 26$.

51. A. de Miguel, Los narcisos, 68-69 y 74 .

52. P. Goodmann, New Reformation. Trad. castellana de A. Abad. Barcelona 1976, 2a., 73-74.

53. J. P. SARTRE, «Materialismo y Revolución». La República del silencio. Trad. castellana de A. L. Bixio. Buenos Aires 1965, 2a, 89. Subrayado mío.

54. R. Bahro, Die Alternative, 111: "Die Losung, dass die Arbeit eine Sache des Ruhms und der Ehre ist, verdeckt ebensowenig wie dass Arbeitsethos des Protestantismus die grundlegende Tasache, dass die industrielle Arbeit, wie sie bis heute vorherrscht, Zwangscharakter trägt». M. FERNÁNDEZ DÉL RIESCO, «El Ethos calvinista y el capitalismo moderno», Estudio Agustiniano, 15 
es un medio de subsistencia. En el futuro no podrá separarse más el trabajo cle la vocación; sin la vocacionalización de la vida el trabajo carece de sentido. El paro, en la línea salarial (poder de adquirir como consecuencia de un trabajo pagado) cada vez será más irreparable. La máquina se impone y sus dueños se concentran. De ahí la llamada a la gratuidad de la vida, tanto más escandalosa en su sentido material cuanto es un privilegio de pocos. El mismo robo se renueva como un hecho mágico de gratuidad: «El robo es quizá el medio más antiguo de evitar el trabajo, y la guerra rivaliza con la magia en sus esfuerzos en conseguir algo por nada, conseguir mujeres sin poseer atractivo personal, lograr poder sin poseer inteligencia y disfrutar de las recompensas de una labor continua y pesada sin haber levantado un dedo en el $\iota$ abajo, o sin haber aprendido un solo conocimiento útil. Tentado por estas posibilidades, el cazador a medida que avanza la civilización se vuelve hacia la conquista sistemática: busca esclavos, botín y funda el estado político con el fin de asegurar y regular el tributo anual, imponiendo, en cambio, una pequeña porción de orden" ${ }^{55}$.

En nuestros días el hombre, más allá de la economía de bienestar, se pregunta por la calidad de la vida: «Es kommt auf die Qualität —und nicht die Quantität- des Lebens an» ${ }^{56}$. No se trata, por tanto de un progreso de simple crecimiento sino de saber cómo se puede cambiar el estilo de vida mismo. No basta crecer en cantidad, se debe crear una nueva sensibilidad, una nueva vida. Este paso no es posible sin otras dimensiones de relaciones humanas. No es suficiente ser útiles a los demás porque así estaríamos aún a nivel de mercancías.

Se impone la necesidad de compartir y convivir la vida como vocación personal y comunitaria y esto no será posible sin superar los dominios de la utilización del hombre por el hombre, donde cada persona adquiera una nueva significación, o mejor dicho, la vida de cada uno cobre verdadero significado. Pues la primera injusticia, de la que nacen todas las demás, es la carencia significativa humana, la presencia de un significado profundo en la vida de cada hombre. Como ha dicho A. Beguin: «No hay nada más pernicioso que lo que violenta el lenguaje, pues la necesidad más honda de los hombres no es la justicia y el orden, sino la significación ${ }^{57}$. Cuando la injusticia aparece, ya hacía tiempo que el otro había dejado de significar algo para nosotros y se había convertido en un objeto manejable y rentable. El mundo del futuro de-

(1980) 50 y ss. A. GluKCSMANn, Les maîtres, 206, ha criticado duramente la militarización del trabajo en el marxismo.

55. L. MumFord, Technics and Civilization. Trad. castellana de Alianza edit., Madrid 1977, 2a., 100. Subrayado mío.

56. E. F. SCHUMACHER, Good Work, 171.

57. Citado por A. HeSnARD, De Freud a Lacan. Trad. castellana de Eds. Mtz Roca. Barcelona 1976, 121. Subrayado mío. 
berá ahondar la relación interpersonal, frente al proceso inconsciente de cosificación utilitaria, donde no sea posible la objetividad sin subjetividad ni la subjetividad sin sus medios apropiados: «Los objetos sin relación constituyen una realidad carente de sentido y las relaciones sin objeto un sentido carente de existencia» ${ }^{58}$. Tal debe ser la ley de toda "oikonomía» que pueda llamarse tal.

Solamente de este modo es posible llegar a una racionalidad concreta y a la vez universal, alejada de los intereses incomunicantes y particularistas cerrados ${ }^{59}$, camino de una auténtica libertad solidaria. No solamente Habernas ha relacionado claramente las tres dimensiones de verdad, libertad y justicia, en la vida humana también en el cristianismo actual se renueva cada vez más el antiguo y primitivo sentido de la comunión en cuanto implica también profunda comunicación, una profundidad que naturalmente, exige manifestarse. A este respecto es muy sugerente la comprensión del espíritu de Jesús como dinamismo fundamental de comunión y comunicación. Aquí me refiero especialmente el escrito de Delzant ${ }^{60}$ que reprensenta un panorama, en cierto sentido desconocido, y que asume la situación actual de la investigación humana tanto a nivel de pensamiento, en general, como en relación a los grupos más vivos del cristianismo actual, superado el espíritu reaccionario del progresismo y del conservadurismo en los años pasados.

Nace ahora de nuevo la posibilidad de una verdadera convivenciacomunión-comunicación, digamos, si parece bien, en libertad y democracia, pero sin la insolencia y el individualismo que siempre las ha unido y también hundido, porque: «La libertà dell'uomo egoista e il riconoscimento di questa libertà è pero puittosto il reconoscimento dello sfrenato movimento degli elementi siprituali e materiali che formano il contenuto della sua vita» ${ }^{61}$. Deberá surgir también una igualdad y una justicia pero no por una compulsión de seguridad que sería más bien la garantía segura del propio egoísmo ${ }^{62}$ donde las relaciones comunitarias o ciudadanas permiten administrar al vecino en beneficio del hombre egoísta hijo de la Gran Niveladora e incapaz de percibir que: «al que le miden mal para que dé la talla no le hacen precisamente un favor ni le ascienden en modo alguno, aunque cierta interesada campechanía de cuartel esté pronta a verlo así» ${ }^{63}$.

Cuando el bien común y el egoísmo individualista entran en relaciones de

58. M. GODELIER, Rationalité et irrationalité en économie. Trad. castellana de N. Blanc, Madrid 1974, 4a., 354.

59. E. Ureña, La teoría crítica de la sociedad de Habermas. Madrid 1978, 103 y 119.

60. A. Delzant, La comunication de Dieu. Paris 1978, 322 y 263 y ss.

61. K. MARX, La questione ebraica e altri scritti giovanili. Trad. italiana de R. Panziere, Roma 1971, 77.

62. K. MARX, La questione ebraica, 73.

63. F. SAvater, Panfleto contra el Todo. Barcelona 1978, 69. 
confusión ${ }^{64}$, la justicia se trasforma en la empresa de los justicieros y manifiesta únicamente el estado de embrutecimiento de las fuerzas rivales alimentadas por cada grupo impositivo. La lucha en favor de la vida se rebaja al combate suburbano y la alcaldada vulgar, mientras los presuntos revolucionarios caen en la tentación del poder por el poder y la razón de la fuerza. Poco a poco se llega al círculo infernal de la violencia según el esquema estímulorespuesta implicativo de una vivencia mercantilizada y competitiva de la autorrealización ${ }^{65}$. Ésta unida a la ansiedad anticipatoria del éxito y la meritocracia avoca al desastre más rotundo de los hombres y los pueblos, porque aquí la meta a conseguir — un éxito inmediato espejeante- funciona como lugar teológico de salvación y como ésta no es posible en la desnuda exterioridad del hombre, éste se convierte en Sísifo desesperado y decididamente perdido.

Perdido el horizonte de la vida y su sentido el escepticismo subterráneo se introduce poco a poco en las raíces del hombre hasta manifestarse por el cinismo en un nihilismo oculto que teme decirse su propio nombre, como es lógico que ocurra en un mundo de bienestar en el que todos debemos estar bien. Entre tanto la confianza en el sentido de la vida se cambia en una fe beligerante por la contraposición, la autonomía individualista, el progreso que viene y el mundo que ha de venir, el contragolpe de paso para el poder, por los bienes abundantes $\mathrm{y}$, en definitiva, por la fuerza biológica ${ }^{66}$. $\mathrm{Fe}$, naturalmente, incrédula y escéptica. De estos engaños nefastos, bajo las mejores intenciones, está llena nuestra historia. El retorno actual de la bellocracia y el pimpante 'fascismo hedonista' ${ }^{67}$ tan pujante nos hacen sospechar que no estamos tan lejos como parece del viejo racismo, abominado oficialmente pero glorificado constantemente por la vida de cada día.

Igualmente el recurso a las masas y al pueblo en todo tiempo y lugar sin distinción ni razón no deja de tener un resabio a dios de mayorías ${ }^{68}$ y un sabor

64. F. Savater, Panfleto, 52 y ss.

65. V. FrankL, Man's Search for Meaning. Trad. castellana de Diorki, Barcelona 1979, 109. La relación frustración-agresión tiene un libro histórico por su calidad, a saber: J. DolLARD \& R. S. SEARS, Frustration and Aggression. Yale 1957, 9a. Romper el círculo reactivo es hoy una clave fundamental para nuestra civilización a fin de superar la agresividad brutalizante de nuestro tiempo. Ello constituye en nuestros dias un signo fundamental de inteligencia.

66. J. HABERMAS, La teoría nihilista del conocimiento en Nietzsche. Trad. castellana de C. García Trevijano y S. Cerra, Valencia 1977, 35.

67. A. BirnBaCher \& Meyer, K. M., Was braucht der Mensch um glück zu sein. München $1979,16$.

68. M. HoRKHeImer, Zur Kritik der instrumentelle Vernunft., 38: «El principio de la mayoría en su forma de juicios generales sobre todo y cada una de las cosas - tal como se está imponiendo, gracias a las modernas técnicas de comunicación y a las votaciones de todo tipo- se ha convertido en una fuerza soberana a la que el pensamiento debe someterse. Es un nuevo Dios, no en el sentido en el que lo conocieron los pioneros de las grandes revoluciones, es decir, como una fuerza de oposición contra la injusticia existente, sino como una fuerza para resistir lo contestatario». Citado en M. Horkheimer, K. Popper, H. MARCUSE, $A$ la búsqueda del sentido. Salamanca 1976, 85. Subrayado mío. 
amargo a las raíces de las fuerzas salvajes de la tierra y su conquista. Y aunque, por pudor, no se desentierre el hacha hay que ver cuán taimados y arteros, como diría Nietzsche, se vuelven los hombres cuando les está vedado recurrir a la fuerza bruta en sus contiendas ${ }^{69}$. Los ídolos, por tanto esperan siempre a la puerta: «No tendrás otros Jeans fuera de mí» ${ }^{70}$ nos dice nuestro mundo industrial.

Esta idolatría - liquidada la dialéctica interioridad y exterioridad- pone al hombre fuera de sí para la caza mágica de los otros con la teatralidad de la vida y sus máscaras como forma aparente de convivencia y estimación. Entonces surge el temor y el terror, la brutalidad y sus ordalías, la inseguridad universal hasta el embrutecimiento que confunde el poder de la voluntad con la voluntad de poder ${ }^{71}$. Semejantes trasvaloraciones han permitido a los saqueadores de la razón el maridaje de pensadores tan lúcidos como Nietzsche con la avidez de la walkirias y eso nos advierte de la conveniencia de ser dolorosamente claros para evitar mayores sufrimientos al presente, y también al futuro.

\section{El espíritu de la resistencia}

Ha llegado el momento de preguntarnos por la forma de resistir a estos desafueros idolátricos, y, en definitiva, ¿qué hacer concretamente? Para empezar conviene aclarar el espíritu de la resistencia. Resistencia no es simple oposición ni principalmente oposición. Como re-nunciar es sobre todo renuntiare, anunciar de nuevo, resistencia es llamar otra vez, de nuevo, a una vida nueva. Resistencia, por tanto, es descubrir o ponerse en una nueva situación, re-sistere, elegir una nueva perspectiva y un nuevo modo de vida. En otro caso volveremos a las andadas porque: «no hay contrapoder que no sea una figura definitiva del Poder expulsado» ${ }^{72} \mathrm{y}$, en esta línea, «toda metafísica es una política» oculta que atrae la violencia porque al tomar posiciones,

69. Nietzsche pensaba que nuestra moral es una creación del resentimiento y una interiorización perversa y reactiva de la venganza y la crueldad: F. NiETZSCHE, Zur Genealogie der Moral. Trad. castellana de A. Sánchez Pascual, Madrid 1979, 4a, 42, 43.

70. Este slogan publicitario resume según P. P. Pasolini el espíritu de la segunda revolución industrial y su trasmutación de valores. Citado por D. SólLE, Wahlt das Leben, 19.

71. Tanto en Nietzsche como en su maestro Schopenhauer hay una ambigüedad soterrada y nunca aclarada entre voluntad y poder, fuerza y vida, espontaneidad y arbitrariedad, vitalidad y destructividad, fiesta y crueldad, etc., que problematiza todo su discurso filosófico. Puede verse al respecto: A. SCHOPENHAUER, $I l$ mondo come volonta è rappresentazione. Trad. italiana de $\mathrm{O}$. Chilesotti, Milano 1888, 80, 84, 140-141, etc. F. NIETZSCHE; Zur Genealogie, 6, 76: «Sin crueldad no hay fiesta: así lo enseña la más antigua, la más larga historia del hombre iy también en la pena hay muchos elementos festivos!». Parece como si Nietzsche al criticar la violencia brutal de su medio social hubiera quedado encantado por ella.

72. B. HENRY-LEVY, La barbarie, 25-26. 
sobre todo posiciones ofensivas, se está invocando la guerra ${ }^{73}$, el enfrentamiento de las potencias teóricas y prácticas.

Por tanto la nueva re-situación no debe tener el carácter de trinchera aunque sí de compañía pero solamente en el sentido originario de acompañar y compañeros. Si realmente hemos de movilizarnos por un mundo nuevo debemos hacerlo como amigos y no como enemigos. Si cedemos a la dialéctica del estímulo y la respuesta, de la frustración y la agresión, habremos dejado de ser resistentes ${ }^{74}$. El hombre de la resistencia solan:ente puede dar una verdadera respuesta a su mundo si ésta no es una simple contestación reactiva antes bien se realiza como una postura res-ponsable, y esto quiere decir que responde y se compromete cada día de nuevo con la nueva vida. Una auténtica resistencia no puede ser nunca la pura continuación de un vacío existencial o social.

El espíritu de la resistencia exige también saber, con cierta clarividencia, que el asunto de la liberación es un largo camino, no va a resolverse probablemente ya mañana por la mañana, resistir no quiere decir, por lo general, conseguir un éxito claro de eficacia inmediata. El progreso continuo y seguro es una doctrina cardinal de la aristocracia del siglo XVIII pero al hombre de la resistencia nunca le debería parecer tan evidente que «el mundo por siempre y siempre continuar(i)á en la misma dirección, haciéndose más humano, más confortable, más pacífico» ${ }^{75}$.

Al mundo de la resistencia las revoluciones repentinas y sus chamanes le suenan a algo bastante ilusorio, en el mejor de los casos, cuando no llegan a ser sencillamente la entronización de la fuerza brutal. Y adviértase de paso que cambiar de amo no suele traer demasiada suerte pues no hay poder que no ponga la mira en la Poder absoluto ${ }^{76}$.

El hombre de la resistencia es una persona, no es un número en la masa, mejor o peor administrada, no es un mero ciudadano clasificado debidamente por la administración. Henry-Levy atribuye al genio del cristianismo el haber creado el principio de personalización ${ }^{77}$. En efecto, en el mundo antiguo el 'principio de individualización', como se le llamaba, no pasaba de ser algo accidental, del orden de la materia, de la física, lejos propiamente del mundo de

73. G. FunKe, Conferencias en Alcalá de Henares. Julio de 1979, 2a. Conferencia. De próxima publicación.

74. V. FRANKL, Man's Search for Meaning, 123.

75. L. MUMFORD, Technics and Civilization, 201.

76. B. Henry-Levy, La barbarie, 134. Conviene no enredarse con el poder ni a nivel de discusión. Se ha dicho 'el poder corrompe', y 'la ausencia de poder más todavía» (Burlingham). Puede verse: CH. JAMBET, G. LARDREAU, El Ángel, Ontología de la Revolución. I. Trad. castellana de A. Cardin, Barcelona 1979, 28 y ss.

77. M. AlCalá, La Ética de la Situación y Th. Steinbüchel. Barcelona 1963, 183 y 193. B. HENRY-LEVy, Le Testament, 102 y ss. 
la forma, de la valoración metafísica. Así el hombre, y la vida de cada hombre, se da como llamado, invitado, vocacionalizado ${ }^{78}$.

De aquí se sigue el principio de responsabilidad: El hombre no puede esconderse en el «culto de una Física», en la veneración de la fuerza, que es «lo contrario de la Ética» y es la «adoración del orden» ${ }^{79}$. El principio de responsabilidad se continúa con el principio de solidaridad: «el solitario será siempre solidario». Este hombre concreto es también la humanidad universal; no se puede ser solidario simplemente para no estar solo, ni se puede vivir encapsulado ${ }^{80}$. Es preciso personalizarse, pues solidaridad tampoco quiere decir complicidad, vocacionalizar la propia vida para ser realmente solidario.

Este hombre de la resistencia luchará por cruzar la frontera del escepticismo para estar plenamente presente en la historia de nuestro mundo pero no por la fuerza del poderoso ni por la atracción animal del grupo, el partido o la clase; ni por un sentido prefabricado del fin como si ya supiera en qué acabará la historia, sino más sencillamente:

1. Por el deseo de vivir en el Bien y no en el Mal, aun con la ambigüedad inherente a toda historia humana y su mundo concreto.

2. Porque el Bien se debe realizar en todo momento, en lo brillante y en lo anodino ${ }^{81}$.

3. Es necesario saber que no se controla el futuro. Por tanto "resistir quiere decir ricominciare a resistir y responder palmo a palmo al 'dramatismo' de la acción histórica que desanima únicamente a los apáticos y abúlicos de la prospectiva" ${ }^{82}$. Lo aparentemente pequeño no tiene por qué ser menos eficaz que lo grande, ni tampoco menos importante.

4. No se emprenderá nada que no sea digno de ser recomenzado con prontitud y siempre de nuevo ${ }^{83}$. Además no se olvidará que los medios dejan su huella en los fines; por tanto aquéllos deben ser dignos de éstos.

5. La verdad «es extraña al orden del político» ${ }^{84}$. Se considerará que cuando todo es política nada es ya propiamente política, por tanto la postura

78. M. Clavel, Ce que je crois. Trad. italiana de Ed. Città Nuova, Roma 1978, 205: «Al limite, no si dovrebbe dire che l'uomo riceve la Rivelazione, ma che l'uomo è rivelato». Como se revela la intimidad en el amor y el amor en la intimidad. M. Clavel, Dieu est Dieu nom de Dieu. Paris 1976, 225: L'homme ne sait, n'a su qu'il est ni qui il est que par Dieu, et plus précisement par le Christ. Et cette révélation est re-creation. L'homme nouveau du christianisme est L'homme retrouvé par-delà le Péché. Et il n'y a pas, il n'y eut jamais, d'autre homme absolument universel et singulier que celui du christianisme.

79. B. Henry-Levy, Le Testament, 171-172.

80. B. Henry-Levy, Le Testament, 213. Aquí el autor cita literalmente a S. Agustín pero sin anotarlo, aunque le nombra al principio del cap. II. Puede verse también: O. NEGT, «Die Abkspselung der Jugend». H. J. Schultz (Hrsg.), Einsamkeit. Stuttgart 1980, 138 y ss.

81. B. HENRY-LeVy, Le Testament, 225 y 227.

82. B. HENRY-LEVY, Idem, 231.

83. B. HENRY-LEVY, Idem, 234.

84. B. Henry-LeVy, Idem, 236 y ss. 
del hombre de la resistencia no puede motejarse de dimisionaria; ¿acaso no pactó, en su día, el comunismo con el nazismo? La política, de por sí, no tiene garantía ética.

6. Por tanto, «sin teóría y sin partido revolucionario practicarás la resistencia» ${ }^{85}$. La teoría y la ideología se confunden mutuamente con facilidad. Además: «Los errores históricos de los hombres no son jamás tan aparentemente buenos y peligrosos como cuando están incorporados en una doctrina formal, capaz de ser expresada en un lema»" ${ }^{86}$. Por otra parte el compromiso supone descomprometerse de muchas tácticas militantes de vía estrecha ${ }^{87}$.

¿Es esto una religión? No creo valga la pena enredarse en las consabidas peroratas sobre religión y ateísmo. Si Marx pudo decir que la religión «es el opio del pueblo», quizá fuera porque Marx entendía o sabía mucho de opios ${ }^{88}$, pero lo que nunca llegó a oler es que cuando desapareciera esa religión, que él llamó opio del pueblo, el opio mismo sería la nueva religión, pero ahora ya sin pueblo. Al matar toda religión muere el pueblo y su esperanza: «la bebida era aún la 'manera más rápida de escapar de Manchester'. La religión dejó de ser para mucha gente el opio de los pobres; en realidad, las minas y las fábricas textiles carecían a menudo de los más sencillos elementos de la más antigua cultura cristiana: Y hubiera sido más cierto decir que el opio se convirtió en la religión del pobre» ${ }^{89}$.

Escuchemos a un gran sacerdote de esta nueva religión: Le vrai Dieu n'est pas mort ni même égaré. Il nous attend simplement au tréfonds de notre esprit. Et seule, $j$ 'en suis convaincu, une spiritualité exacerbée, ou mieux, parce que plus rapide une drogue psychédélique peut nous conduire jusqu'à cet Infini Pouvoir ${ }^{90}$.

Para el hombre de nuestros días esto es una evidencia: quien no va a las iglesias de antes es fácil que vaya a los fumaderos, a las capillas del alcohol y similares. El psicoledismo, más o menos vulgar, cumple precisamente a la perfección el programa de dotar al hombre de un Poder Infinito y traer ese poder del cielo a la tierra, como tanto ha reclamado el marxismo ante el Dios del

85. B. Henry-Levy, Idem, 239, y M. Clavel, Dieu est Dieu, 297: «Révolution donc, sans idéologie ni tactique».

86. L. MUNFORD, Technics and Civilization, 417.

87. J. EstruCH, «Creer no es comprometerse», El Ciervo, 345 (1979) 8-11.

88. B. HeNRY-LeVY, «El marxismo, opio de los pueblos», La barbarie, 167-186.

89. L. MUMFORD, Technics and Civilization, 198. Algunos marxistas parecen comenzar a pensar: puesto que el opio religioso, como los pobres, siempre lo tendremos entre nosotros, procuremos que sea lo menos malo posible: C. Luporini, J. HromadKa, Partner von morgen? Stuttgart 1968.

Affadamos de paso aquí que la idea de pueblo es una de las más irracionalmente glorificadas, quizá porque en él se incluye todo mundo: C. DIAZ, El anarquismo. Como fenómeno políticomoral, Madrid 1978, 96 y ss. M. STIRnER, Der Einzige, 80 y 155.

90. M. Lancelot, Je veux, 74. 
cristianismo. Por desgracia en cuanto a ese 'Infini Pouvoir' se le convierte a la tierra totalmente en seguida se produce el Estado infinito y mortal como demuestra la historia. No en vano las leyendas orientales nos hablan de la orden de los asesinos (axixinos) animada por el hachis (axis).

El culto del hombre iniciado en la sala de fiestas, entre las nuevas luces, pasa a ser lucha de bandas ciudadanas y termina por la destrucción del rival en la zona suburbana o también más finamente en la gran city administrativa. Así el totalitarismo grupal, bajo el señuelo de la libertad, va a ser una carectarística fundamental y nada positiva de nuestra época. Nadie sospechaba ni podía augurar tanta persistencia a este 'cuba-libre' mezcla de revolución y coca-cola, producto netamente genuino de las nuevas técnicas del capital; pero ahí está: Lo que la nueva generación realiza, es el escepticismo del capital, su nihilismo, no hay cosas, no hay personas, no hay fronteras, no hay saberes, no hay creencias, no hay razones para vivir o morir ${ }^{91}$.

A Marx nunca le pasó por la cabeza que un día surgirían los hijos de $\mathrm{K}$. Marx y Coca-cola — «Kinder von Marx und Coca-cola $»{ }^{92}$, mezcla de consumismo y revolución que van gritando libertad con la coca-cola en mano ${ }^{93}$. Se trata de una generación ansiosa de casi todo, temerosa del fin del mundo, de ese mundo de su vivir y su gozar de apariencias infinitas. Es el afán de exprimir, antes de que todo acabe: «Vivir bien es la mejor venganza (Nobile)» ${ }^{94}$. El hombre convertido en ídolo tiene miedo de su fin. Un secreto terror de su falsa divinidad invade la idolatría con el escepticismo. He aquí el desencanto de nuestro tiempo. El fin de un mito persistente. Herida de muerte la nueva creencia, se sale a todo correr de sus capillas musicales psicodélicas a la desbandada, sin saber propiamente a dónde ir.

\section{Propuestas para otro hombre}

Al homo sapiens le sustituyó el homo faber, ¿no hemos visto pasar nosotros o rondar al menos nuestras tierras al homo ludens? ${ }^{95}$. El evangelio del hombre de la fábrica, el trabajo, ni como esencia del hombre ni como autorealización, ni siquiera en el tono moralizante en que lo predicaba Carlyle tiene credibilidad. Como creador del hombre siempre acaba con él. Al homo faber le ha matado la mina de donde salía todo menos el minero.

91. CH. Jambet, G. LaRdReaU, El Angel, 226.

92. R. Oltmanns, Du hast keine Chance, aber nutze sie. Eine Jugend steigt aus. Reinbek 1980,27 y 87.

93. D. NATAL, "Jean Paul Sartre o la libertad frente a la brutalidad», El Norte de Castilla, 24-4-80, 20. El teórico anarquista Paul Goodmann ha analizado muy bien este asunto: o.c. en la nota 52 .

94. A. de Miguel, Los Narcisos, 46.

95. J. HuizingA, Homo Ludens. Vom Ursprung der Kultur im Spiel. Reinbek 1956. Hay trad. castellana en Alianza Ed. 
Entonces el trabajo será muy importante pero como realización de una vocación previa, no como confusión de vocación y profesión (Beruf) ${ }^{96}$. Por tanto a la buena nueva del trabajo le anteponemos la buena nueva de la vida, y la vida tiene un sentido y un contenido vocacional; sin vocación no hay calidad de vida, $\mathrm{y}$, como había dicho $\mathrm{G}$. Marañón vocación y ética marchan unidas. La política sin la ética, es el trabajo sin la vocación, destruye; y el hombre político sin ética no es propiamente hombre sino un ejemplar rapaz de la raza humana ${ }^{97}$.

Como dijo muy bien Camus en toda verdadera revolución hay siempre «una reivindicación del sentido de la vida ${ }^{98}$, mientras que en la algarabía políticológica encontramos la acción sin la vocación, la organización sin la relación humana, los hechos sin saber qué hacer, el consumo sin gusto ni horizonte alguno.

El homo ludens debería ser, según anunciara también Camus recogiendo una extraordinaria intuición de Nietzsche, «la 'inocencia y el olvido, un volver a empezar, un juego, una rueda que gira por sí misma, un primer movimiento, el don sagrado de decir sí'. El mundo es divino porque es gratuito. Por eso es por lo que solamente el arte, a causa de su igual gratuidad, es capaz de aprehenderlo" ${ }^{99}$. Con este juego de la inocencia y la gratuidad se rompe el imperio matemático de la cuantificación progresista frente a la cualidad, sólo la gratuidad puede dejar atrás el mundo del mercantilismo y la explotación. Solamente la gratuidad es gratuita y tiene gracia. Más allá de la necesidad y el determinismo está el hombre nuevo de la gratuidad y la gracia: «Eso empero es la dimensión de la gracia, la que ya como dimensión está cerrada si la apertura del ser no está iluminada y en su iluminación cercana al hombre. Tal vez consiste lo característico de esta época en el cierre de la dimensión de la gracia. Tal vez es ésta la única desgracia» ${ }^{100 .}$

La ausencia de la gratuidad, la imposición en todo de la compra-venta, el arrivismo del poder, es la característica del mundo mercantil que invade hasta los últimos resquicios de la intimidad humana. Por eso ante la gratuidad se tambalea el sistema sin mediación alguna de violencia. Pero, como ha descrito muy bien $\mathrm{E}$. Tierno Galván para otros tiempos, la concepción pragmática del mundo vuelve o intenta volver siempre según estos presupuestos:

96. M. WEBER, L'Éthique protestante et l'esprit du capitalisme. Trad. francesa de J. Chavy, Paris 1967, 2a., 83-90.

97. M. STIRNER, Der Einzige, 89.

98. A. CAmus, L'homme révolté. 129. Citado por R. MuCCHIELI, Le mythe de la cité idéale. Paris 1960, 18.

99. A. Camus, L'homme révolté. Trad'. castellana de L. Echávarri, Buenos Aires 1975, 8a., 72. Subrayados míos.

100. M. HeIDEgGer, Uber den Humanismus, Trad. castellana de R. G. Girardot, Madrid 1966, 2a., 53. Subrayados míos. 
«a) Es necesario orden político y orden social para que 'triunfar' tenga sentido.

b) El triunfo es el resultado de la racionalización de nuestra conducta y del mundo.

c) Triunfar significa tener poder económico, poder social y poder político» ${ }^{101}$.

Mientras este substrato aparentemente necesario para la realización del hombre permanezca, el cambio de cualidad de vida no será viable. Consciente o inconscientemente se apoyan los mismos valores de la polis dominante, y por tanto el único objetivo es solamente llegar al poder, no cambiar la vida. Y hasta tal punto es así que cuando un hombre político hace un gesto ético no suele tener credibilidad.

El homo faber y su representante el político es industrioso, frío calculador, nunca gratuito, mientras el homo ludens es aparentemente utópico, generalmente generoso y, en lo posible, alegre. La utopía desesteriliza la norma de las cuantificaciones pero no se opone a la vida como vocación, a la creatividad permanente y es la universalidad en lo concreto. Su libertad no es arbitrariedad sino solidaridad, siempre cuidadosa. Así se origina una nueva sensibilidad no racionalista (homo sapiens) ni puramente empirista (homo faber).

No se busca aquí un simple crecimiento mayor ${ }^{102}$, se quiere descubrir de nuevo la vida y su propio sentido sin el cual todo se vuelve absurdo como se experimenta fácilmente en nuestros días: Una nueva forma de vivir y gozar la naturaleza, el mundo recuperado en la nueva sensibilidad por la liberación dialéctica recíproca de la persona humana y el mundo objetivo como había preconizado últimamente Marcuse ${ }^{103}$. Por ahí apuntan los mejores movimientos ecologistas y la «larga marcha a través de las instituciones» reunidos en R. Dutschke ${ }^{104}$.

Aquí cuentan definitivamente las relaciones interpersonales: «L'innamoramento è una rivoluzione» ${ }^{105}$ para la animación profunda de una verdadera transformación y recreación de una límpida opinión pública en la línea de la nueva sensibilidad sin la cual ningún cambio será posible en el futuro. También es decisiva la práctica de un trabajo realmente humano pacificado y creativo como desarrollo de una vocación a las tareas de la teoría y de la praxis en la corriente de la vida, olvidados los tambores de la violencia ${ }^{106}$. Solamente

101. E. Tierno Galvan, Idealismo y pragmatismo en el s. XIX español. Madrid 1977, 99.

102. G. AltNer, Leidenschaft für das Ganze. Berlin 1980, 24.

103. H. MARCuSE, Counterrevolution and Revolt. Trad. alemana a cargo de A. Schmidt. Frankfurt a. M., 1973, 89.

104. R. DutSChKE, «Textos», El Viejo Topo, 41 (1980) 13.

105. .F. Alberoni, Innamoramento e Amore. Nascita e sviluppo di una dirompente, lacerante, creátiva forza rivoluzionaria. Milano 1979, 88.

106. J.-M. Muller, L'Évangile de la non-violence. Paris 1969, 36. 
así se posibilita una ética del apoyo mutuo ${ }^{107}$ frente a la competitividad y la lucha que es la guerra de otros tiempos con ropajes civilizados, pero al fin y al cabo guerra, en la que - en el mejor de los casos- se sustituye el homicidio por el suicidio, la muerte por la destrucción.

En esta alternativa del juego creador al trabajo esclavizado, de la sencillez al consumo, de la gratuidad a la necesidad, de la ética a la política, no deben introducirse ya nunca más como virtudes del tiempo la irresponsabilidad, el aislamiento individualista, la complicidad aparentemente solidaria, ni tampoco la arbitrariedad ${ }^{108}$ o la destructividad irracional tan socorridas en los últimos tiempos.

Si bien es cierto que las nuevas generaciones han incurrido más frecuentemente en estas contradicciones no lo es menos que han sabido ser muchas veces también sus mejores críticos. Digamos también en su descargo, que siempre se equivoca más quien está más comprometido con los problemas acuciantes. Y puede añadirse que la velocidad del cambio, el sentido de provisionalidad universal y el espíritu nómada planetario han propiciado la irreflexión más allá probablemente de las responsabilidades personales ${ }^{109}$.

El mundo abierto ${ }^{110}$, la economía de la incertidumbre ${ }^{111}$, la teoría de los juegos y la relatividad impuesta por la ciencia física se han fortalecido cada día ${ }^{112}$. Así el in-formalismo se ha configurado como la clave epistemológica de nuestro tiempo, donde por una parte se abre un gran espacio de libertad pero también un campo enorme de desorientación. La multiplicación insospechada de posibilidades y opciones a todos los niveles, especialmente en algunos grupos sociales que en principio tienden a generalizarse tiene en todo ello su parte notable de influencia ${ }^{113}$.

Puede decirse que ante esta avalancha neotécnica el hombre de nuestro tiempo no ha tenido aún capacidad ni habilidad suficiente para situarse activamente, en general, ni a nivel de información ni en punto a formación. La estrategia de la anticipación ${ }^{114}$ no ha conseguido llegar a tiempo y la pragmática de la producción ha funcionado por encima de los hombres. Éstos han padecido la impresión y el desconcierto de andar a la deriva, de modo que aun los mejor dispuestos, si se nos pudiera incluir, hemos andado en luchas inúti-

107. C. DiAz, El Anarquismo, 43 y ss.

108. T. RosZAK, The making of a counter-culture. Trad. castellana de edic. Kairós, Barcelona 1970,30 .

109. A. Toffler, Future Shock. Trad. castellana de J. Aleu, Barcelona 1973, 61 y 83.

110. U. Eco, Opera aperta. Trad. castellana de R. Berdagué, Barcelona 1979, 216.

111. K. H. BORCH, La economía de la incertidumbre. Trad. castellana de J. Melgar B., Madrid 1977.

112. K. HUBNER, Kritik der wissenschaftlichen Vernunft. Freiburg 1978, 147 y ss.

113. A. TOFFLER, Future Shock, 323 y ss.

114. A. TOFFLER, Future Shock, 585. 
les y debemos decir aquellos versos preciosos de B. Brecht: «...Nosotros,/ que hemos querido preparar el terreno para la amabilidad,/ no pudimos ser amables»" ${ }^{115}$.

Ahora las aguas parecen remansarse poco a poco y puede asegurarse, con precaución, que la serenidad se extiende suavemente. El hombre ha alcanzado nuevos horizontes y reemprende de nuevo su ruta con pasos cuidadosos en una perspectiva de nuevas claridades. La nueva humanidad más sencilla y humilde pero también más concreta y realista parece decidida para iniciar, aunque titubeante, nuevos caminos.

Si la nueva sensibilidad llega a imponerse con sus calidades tendremos un mundo con sentido de su vocación en vez del antiguo esclavo de sus afanes. El hombre alegre por los caminos de la libertad sustituirá a la tristeza de las imposiciones de lo siempre necesario. La creatividad podrá adelantar a la rutina y a la acedia siempre antigua y siempre nueva que hoy se llama pasotismo. Aparecerá un mundo sencillo y abierto en lugar de la avidez acaparadora dominante. Tendremos un hombre de vocaciones e invitación frente al hombre de la fuerza, una humanidad ética frente a la masificación política. Cuando esto pueda ocurrir, y deberá ser pronto si no queremos destruirnos más, nuestro mundo tendrá una vida nueva, de reconciliaciones entre interioridad y exterioridad, conciencia y naturaleza, de lo sublime y lo inferior, del infinito y lo finito...

Entre tanto hagamos lo que podamos con sentido solidario pero sin convertirnos en cómplices porque, como recordaremos siempre, los medios dejan su huella en los fines...

Domingo NATAL

115. Citado por E. BALDUCCI, «La ciudad del sol», Iglesia Viva, 85 (1980) 23. 